\title{
Partial Ownership for Outer Space Resources
}

\author{
Erwan Beauvois $^{1}$. Guillaume Thirion ${ }^{2}$ \\ Received: 19 September 2019 / Accepted: 30 January 2020 / Published online: 19 February 2020 \\ (c) The Author(s) 2020, corrected publication 2020
}

\begin{abstract}
The most widely adopted agreement on space law, the Outer Space Treaty (OST) (1967), actively promotes international partnerships and peaceful uses of outer space. It also forbids any claims of sovereignty or private property on celestial bodies; however, nothing is explicitly written about the use of resources that can be found there. Other texts, like the Moon Agreement (1979), attempted to extend provisions on this regard, but only 18 nations ratified this agreement, probably because it also contains obligations that remove all incentives for the private industry to participate in the exploitation of outer space resources, such as the obligation to disclose all discoveries and share the benefits between all state parties. Today, most missions are scientific, so there is no need to compete for using space resources. If tomorrow society wants to incentivize participation, and leverage the available funds, from the private sector to explore and exploit outer space, an allocation mechanism that allows to dispute the use of resources needs to be set up. On Earth, this is achieved by the private property system and commercial competition. However, private property is not allowed by the OST, because it has a right of exclusion, and everyone shall be free to use space resources if it does not interfere with activities of other nations. An exclusivity of use for the first nation to exploit a given resource is not desired either and is precisely why the OST was established in the first place. In full compliance with the OST, this paper introduces the concept of Partial Ownership of Outer Space Resources (POOSR). This system allows to compete for the use of resources, without granting monopoly, as it always keeps the competition for ownership open. It is based on the introduction of a Harberger tax and a Partial Ownership system, that allows to expose commonly-owned resources (such as outer space asteroids, or planetary surface areas) to the efficiency of allocation provided by market dynamics, while preserving the incentives for investment to the current owners and preventing resource locking. This paper shows how such system would foster investments from private entities, as well as how it would benefit to all the international entities or nations participating to it. The synergy between such system, international regulations, and national laws, to establish a regulation for space mining and other outer space activities is also discussed.
\end{abstract}

Keywords Space mining $\cdot$ Law $\cdot$ Governance $\cdot$ Economics $\cdot$ Ethics $\cdot$ Partial ownership

An efficient allocation mechanism for outer space resources that is friendly to the private sector, but without private property, preserving outer space as "the province of all mankind".

Erwan Beauvois

beauvois.erwan@gmail.com

Guillaume Thirion

guillaume.thirion@isae-alumni.net

1 International Master SEEDS, Politecnico Di Torino, Torino, Italy

2 International Master SEEDS, ISAE-Supaéro, Toulouse, France

\section{Governance}

Exploring new planetary bodies and exploiting their resources to set up a sustainable space infrastructure is a medium-term objective for all major space-faring nations, but how can we organize to get there? How can international collaboration be fostered to decide common policies, tackle common issues, preserve sovereignty of the nations, and stimulate economic growth of all the participants?

This section introduces current space agreements and proposes a governance structure for international collaboration on large scale projects like Asteroid Mining, Moon exploration, and Mars settlement. A decision-making process that is compatible with specialized interests is introduced, and it 
is discussed the role of private companies, as well as some ethical considerations.

\subsection{Current situation}

Conquering the new frontier by returning to the Moon, sending humans to Mars, and unlocking the Asteroids resources is a unique opportunity to capitalize on our human experience and think about how we could organize space societies, and offer a fresh start to a new branch of civilization, by fostering international collaborations and address the legal challenges faced by space mining today.

That being said, the next humans returning to the Moon, and the first who will set foot on Asteroids and on Mars will not be founding a colony or establishing a society but conducting a space exploration mission. Few astronauts will get there at first, perhaps only for short stay missions. Then regular manned missions will be conducted, from multiple agencies, and perhaps even by private companies. It does anyway sound a bit far-fetched to talk about a "civilization" when we are actually talking about only a few people at first.

The initial "flag" missions will probably be conducted without much concerns about an outer space governance structure. But as humankind progresses towards its space exploration endeavours, we observe that nations and space agencies push toward collaboration over competition. Big projects like the ISS, Hubble Space Telescope, or rovers, are conducted as an international effort, and alliances like the ISECG (International Space Exploration Coordination Group) are formed to establish common goals and a Global Exploration Roadmap (GER) [1].

The Outer Space Treaty [2], established in 1967, has been ratified by 108 countries and signed by 23 more. It is an agreement between the major space-faring nations to establish a baseline legal framework regulating space exploration. It actively promotes international partnerships, peaceful use of space, and introduces several concepts that are important to note before thinking about a governance structure for outer space resources:

- "There shall be free access to all areas of celestial bodies" Art. I.

- "Outer space, including the Moon and other celestial bodies, is not subject to national appropriation by claim of sovereignty" Art. II.

- "State Parties to the Treaty shall bear international responsibility for national activities in outer space, including the Moon and other celestial bodies, whether such activities are carried on by governmental agencies or by nongovernmental entities" Art. VI.

- A nation shall not have "potentially harmful interference with activities [of other nations] in the peaceful exploration and use of outer space" Art. IX.
In other words, there should be no private property in space, because it would introduce a right to exclude others, and to prevent them from using a property. It would not comply with the principles of the OST, as every land shall remain "the province of all mankind" and there shall be "free use", if it does not interfere with activities of other nations. Also, nations are responsible for their private companies and citizens actions in space. This prohibition of private property is subject to interpretation and several national laws, like in the U.S.A. and Luxembourg, are materializing a different interpretation and are essentially granting their companies a right to claim private property in space. In 2015, the US Commercial Space Launch Competitiveness Act (HR 2262) of the Obama Administration states in Title IV_-"Space Resource Exploration and Utilization" that the USA must facilitate the recovery of resources coming from space for all its citizens. This resources appropriation, even if facilitated and even sometimes funded by the American government, does not impose American sovereignty on the celestial bodies according to the Act. In 2017, Luxembourg took inspiration from the USA and passed a space law stating in its first article that space resources are allowed for appropriation if the operator is settled in the country and has an approval of the Ministry in charge of economy and space exploration. National legislations are a good strategy to offer guarantees for private investments, but do not offer a satisfactory conflict resolving mechanism, and will probably cause problems in the future when multiple nations will be interested by the same resources (certain orbits, asteroids, or areas of the Moon and Mars certainly have special value).

A dynamic where nations play with their regulatory framework to attract private space companies on their land is taking place. A trade-off must be performed by every nation, as more flexible laws will attract more companies, but also increase the risk of those companies inadvertently crossing some forbidden lines (pollution, generation of debris, contamination, ...), for which the nation will be held responsible for.

Indeed, this increase in national legislations asks the question of whether the future of space law resides in international right or if it will be driven by national laws, which can only be enforced in state's territorial jurisdiction. The question of the use of outer space resources needs to be answered, and an allocation mechanism and authority needs to be internationally agreed in order to prevent conflicts between nations.

\subsection{Analogous Situations}

To justify outer space resources utilization, states usually take inspiration from the United Nations Convention on the Law of the Sea (UNCLOS) which inspired the OST. Article 136 states that "The Area and its resources are the common heritage of mankind" where "The Area" refers to "the seabed and ocean floor and subsoil thereof, beyond the limits 
of national jurisdiction". Then, the international seas use is based on the freedom principle notably of circulation or fishing with only limitations due to the international law with fishing quotas for example. However, this case of the UNCLOS can find its opposite in the specific case of Antarctica usage which is a transposition on Earth of some principles of the OST. The Protocol on Environmental Protection to the Antarctic Treaty (1991) provides for comprehensive protection of Antarctica, the last great wilderness on earth. The countries which ratified the Protocol commit to comprehensively protect the environment of the Antarctic region and dependent and associated ecosystems. Among other, if Antarctica is designed as a "natural reserve, devoted to peace and science", all mining activities are banned indefinitely stating in Article 7 "Any activity relating to mineral resources, other than scientific research, shall be prohibited". Contrary to a common misconception, there is no time limit on the mining ban and there are strict rules for modifying the ban.

Until 2048, the unanimous agreement of all countries engaged in the management and governance of this territory would be required to remove the mining ban. Later that time, any country may request to review this ban in a conference in which three quarters of the countries which adopted the Protocol in 1991 adopt the modification and three quarters of the countries implement it (of which, all signatories from 1991) to enter the modification into force. In addition, any amendment removing the mining ban can only occur if a legal regime for controlling mining is in force and if the sovereign interests of countries under Article IV of the Antarctic Treaty were safeguarded. Unless an amendment is adopted in the manner set out above, the mining ban will remain in force indefinitely. Taking inspiration from Antarctica, a collaboration between nations to establish an enforceable legal framework to govern the use of outer space resources in a responsible way can be established.

Whether it is on the legal or engineering side of things, there is value in collaborating, and it is ultimately more beneficial for every nation to do so. Countries who were denied entry in the ISS program like China greatly suffer from this rejection, as it impairs a bigger financial charge upon them to benefit from the same technological advancements and scientific knowledge. A proposition for governance and economic structure for outer space exploration and exploitation that is both inclusive, in line with the existing laws, guarantees proportional returns on investments, and lays the foundations for a future space-based society, is detailed in the following paragraphs.

\subsection{Outer Space Alliance}

On Earth, a new intergovernmental organization is founded. For this document, we will call such an organization the Outer
Space Alliance (OSA). Following the model of the United Nations (UN), every country is free to join: it is "open to all peace-loving States that accept the obligations contained in the Charter and, in the judgment of the Organization, are able to carry out these obligations" [3]. While very similar, it will be explained later why it is important that such an organization remains independent from the UN and cannot be created as a specialized agency within the UN.

Much like the governance model of the European Space Agency (ESA), all member states are given an equal amount of voting power, regardless of their financial contribution. Countries with higher financial participation are compensated by being awarded more contracts from the OSA. This concept is called geographical return and guarantees a proportional return on investment to every participant: if the U.S.A. are funding $35 \%$ of the OSA, $35 \%$ of the awarded contracts value will go to the American industry. There might be a required minimum contribution and mandatory projects so only countries that plan to have a participation in space exploration activities shall join the OSA.

As a space-faring nation, joining the OSA is optional, but since the geographical return makes almost every spending come back inside the country, it does not cost a lot to participate in it, and can be seen more as an investment. National agencies are still relevant for national programs, but the OSA provides a convenient structure for international cooperation, building common space infrastructure, and establishing an international law framework. Countries not participating to the OSA would be facing a much more coordinated and organized coalitions of nations, and undertaking actions contrary to the OSA charter could result in coordinated commercial embargo on Earth or other pressure mechanisms, while also being prohibited from using the common space infrastructures and capabilities.

\subsection{Radical democracy}

As mentioned, member states are free to modify their own national laws to favour certain kind of activities in space (think of Luxembourg and the U.S.A. regarding Space Mining). Certain countries might have a leading industry in the sector of transportation, while others are more performing in human spaceflight, life support systems, in-situ resource utilization (ISRU), etc. Therefore, all member states will have stronger preferences and stronger interests in certain decisions, while they may not care as much about other subjects. A traditional voting system (1-person 1 vote, $1 \mathrm{P} 1 \mathrm{~V}$ ) does not allow to capture different degrees of caring, and this is a problem for dealing with a large international project like space exploration that envelops such a big variety of different topics. It could be interesting to make use of quadratic voting, as introduced in [4] and discussed in-depth by Glen Weyl in his Radical Markets book [5]. Under such a system, every mem- 
ber state would be given a certain amount of Voice Credits, for free, every year. When a new issue arises, and a decision must be taken, member states can purchase votes with their Voice Credits, with the cost of an additional vote increasing quadratically with the number of already purchased votes, hence the name of quadratic voting $\left(\operatorname{cost}=\right.$ votes $\left.^{2}\right)$, or radical democracy $($ votes $=\sqrt{ }$ cost). This scaling speed is not arbitrary and while out of topic for this paper, it is explained in depth in the book why quadratic scaling is the just price to pay for imposing your preferences upon others. Let's provide some examples to understand how such a system would work:

- A decision regarding space transportation must be taken. With its strong private launchers industry, the U.S. is caring a lot about this issue and is buying 5 votes at the cost of 25 Voice Credits. On the other hand, the Netherlands has no launcher program and other priorities, so they save their Voice Credits for later, buying 1 vote at the cost of 1 Voice Credit.

- Being a major reference in building human-rated space habitats, Italy cares a lot about Human Spaceflight and casts 3 votes on each issue, costing 9 Voice Credits each time. While Japan is more focused on robotic exploration and only uses 1 vote costing 1 Voice Credit on each issue. Japan has a larger remaining budget of Voice Credits and when decisions impacting robotic exploration will arise, they will be able to have a bigger impact.

As mentioned in Radical Markets [5] (this paragraph is almost entirely quoted), this voting system still has flaws: it is not resistant to collusion, vote-buying, or fraud. But so are 1 person 1 vote systems. A separate law enforcement mechanism needs to be in place. Quadratic Voting, however, deals better with minorities and specialized interests. Small groups may still lose to the majority, but they will not lose to a majority with weak preferences. Majorities will prevail over minorities, as they should, when the intensities of everyone's preferences are similar. But when minorities have sufficiently intense interests, they can protect their interests from majority domination.

\subsection{Private Companies}

Many space enthusiasts believe that private companies will lead the way in space exploration. Under such assumptions, one could argue that private companies should be able to join the OSA on the same basis as nations can and that there could be a race opposing public vs. private initiatives. It would be interesting to study how private companies and nations could be composing an international organization, but, given the current state of space law, companies are not considered as separate entities but as representatives of their parent nation.
Moreover, many private companies are strong thanks to collaborations and contracts with their nation's space agency, government, or military, so the relationship is more of a partnership than a competition. In any case, should a private company threaten a nation's supremacy or diplomatic relations, most of the company's activities are still Earthbased and it is hard to see how a nation would accept such behaviour, therefore repressing the company's enactments as any other illegal acts. Keeping participation at nation level in the OSA also allows for more flexibility. Nations with an entrepreneurial mindset could put in place a system where their voting power is directly managed by their corporations, while some others might prefer a different approach. The U.S.A. for instance has put in place a national regulation to transfer property and liability of their activities in space to the underlying company doing activities in space. In any case, companies are still paying taxes in their own country, create domestic employment, and participate in economic growth, so all nations will vote in the best interest of their industry.

\subsection{Protected Areas}

Planetary exploration cannot be wildly conducted, and some rules need to be respected. For instance, the topics of contamination, planetary protection, and preserving scientific integrity, are agreed by everyone to be of top priority, when they are justified. In fact, some of them are included in international treaties, like contamination is mentioned in OST Art. IX [2]. The Moon and Mars hold a lot of scientific value, and some areas should be protected from any interaction to conserve the environment as pristine as possible.

When industries are set up on other planetary bodies, the environment will undergo deep, irreversible changes. Habitat zones will have pipe networks and pressurized environments that will eventually leak. Industrial zones, and especially mines, will modify the terrain. All these installations will also produce waste (unrecycled biological wastes, processed regolith, broken parts, leakages, ...), that will compromise the scientific integrity of some areas, and perhaps make them unusable in the short-medium term. Some historic sites like the Apollo landing sites, as well as the areas surrounding current and past rovers, and well as some identified unique geologic formations, might be suited for protection to prevent them from being tampered. To structure our upcoming use of the resources of the Moon, for instance, a network of "moonways" could be decided, to make sure all commercial transport elements would be taking the same path between 2 industrial sites. This would start discussions about protection of our common lunar heritage and establish a coordination between nations to put in place regulations. Scientific exploration would not need to be regulated, because the number of travels will be less, and they are less likely to repeatedly drive in the same areas. 
To address these pollution and preservation issues, several areas shall be defined: habitable areas, restricted areas, scientific areas, waste areas, and moonways. To avoid conflicts of interests, these will have to be defined by another impartial entity, separate from the OSA. This entity shall not have economic interests that would bias its judgement. A good candidate for such a task would be the UN, that has a dedicated bureau for space-related issues, the UNOOSA. Prior to defining an area, sample analysis could be performed, when needed, and regularly other samples could also be analysed to monitor the environment's evolution. Those areas are not only required for scientific, regulatory, and ethical reasons, but also for market efficiency reasons. An entity having the monopoly of a given natural resource or location is not desirable, it might as well be regulated and allowed for use under special requests only.

\subsection{Space Citizens}

A more distant-future prospect, and idealistic suggestion perhaps, would be to put in place a Space Citizenship programme. Astronauts and settlers staying in outer space would likely want to participate in the development of the rules they will live under [6]. Gradually transitioning the decision power to space workers and settlers by providing them with Voice Credits could be desirable. Large contributors to the space development effort residing on Earth could also be considered, as an honorary gift for helping advance humanity's progress towards the stars.

\subsection{Developing Countries}

Another concern is the inclusion of developing countries in this space expansion movement. The OST states that exploration "shall be carried out for the benefit and in the interests of all countries, irrespective of their degree of economic or scientific development, and shall be the province of all mankind", but the reality is less egalitarian notably when analyzing the lack of implication of African States in space programs. Nigeria is one of the few space nations of this continent and seems to be far from the race of commercialization of space. Algeria is preparing its future law about space operations, but they are likely to give the monopole to the state in these activities. That seems to be a risky bet as the private sector is becoming more and more predominant.

\section{Economic Structure}

How to design an efficient economy for a life-threatening environment in which nothing can be owned? In this section are addressed the following main questions: How to design an economy compliant with the existing regulations? How to benefit from efficient market mechanics without private property? How to bootstrap a space economy from scratch, leveraging the funding capacities of the private sector? How to incentivize space work and settlement for the middle-class, and why is it desirable?

\subsection{Partial Ownership}

After an internationally recognized authority regulating space exploration is in place (see Governance Sect. 1). An economy whose rules of good conduct are enforced by this authority can be set up. An idea suggested by R. Zubrin in 1995 [7] is to allow Martian land to be sold, leveraging the funds available in the private sector by allowing speculation. However, that could result in inefficient use of land since someone might just buy a land without making use of it, and as discussed previously, according to international agreements [2], nothing can be privately owned, so how could we make those lands available for purchase, and commercial use?

No private property does not mean no market. While outer space resources cannot be owned, a common interpretation of the OST is that they can be used. The Moon Treaty [8] of 1979 attempts to clarify this point and states that "States Parties to this Agreement hereby undertake to establish an international regime, including appropriate procedures, to govern the exploitation of the natural resources of the moon as such exploitation is about to become feasible”. Indeed, rules for governing the use of outer space resources are required, but this treaty does not define them, it only contains an engagement to establish a legal framework as soon as outer space resources exploitation becomes possible. Think about the thin band of land almost permanently illuminated on some mountains or crater rims of the lunar south pole, where the highest concentrations of water have been observed. These lands have special value, and this situation can be transposed to Mars, where geothermal sources and metal deposits will be located. Asteroids are in the same boat. There will be commercial incentives to use outer space resources: an allocation mechanism must be enforced, and a market to dispute the use of those resources could be desirable, as markets come with an efficient allocation of resources.

Harberger licensing [5] is a partial ownership system that allows exposing public goods and government-owned natural resources to the efficiency of allocation provided by market dynamics while preserving the incentives for investment to the current owners, and preventing monopoly (resources locking, or location squatting). Under such a system, owners self-assess the value of their properties and pay a tax proportional to this value. If a buyer is willing to purchase something at the owner's self-assessed price, the owner must cede this good to the buyer. No owner would be ceding a property without being paid what she considers a good price 
for it, and a counter-claim allowing the owner to raise his self-assessed value to conserve ownership could be put in place. In his Radical Markets book [5], E. Glen Weyl names this tax common ownership self-assessed tax (COST). Such a permanent auctioning system ensures that the person who values the most a property can always benefit from it. This mechanism is already in use for online advertisement space allocation and is particularly adapted to the private exploitation of public goods, such as radiofrequency bands, outer space special locations like geostationary orbits, and celestial bodies surface areas. This system is comparable to licensing but overcome some drawbacks like having to trade-off between allocative efficiency and incentives to invest (you'd want to provide long-term licenses so that owners have an incentive to invest to improve this public good, however, the longer the license, the fewer competitors can challenge the efficient use of the licensed good).

Such a system would be compatible with the Outer Space Treaty [2]. First, there is no appropriation or claim of sovereignty from any nation or company: everything still belongs to the international community (through the OSA). It is only a structure to allocate the use of space resources, that relies on a small tax to introduce market dynamics. That tax benefits everyone who accepts to pay it, as they are also shareholders of the OSA, the entity collecting those taxes. There is no private property, so no right of exclusion, so everyone remains free to access all areas of outer space, if it does not have potential harmful interference with activities of others, as depicted in the OST. The current owner could prevent others from using a property on behalf of harmful interference, but everyone remains free to acquire the use rights of the property, so there is no real exclusion. The collected taxes could also be used to redistribute wealth, if desired, enabling developing countries to catch up in space activities and increasing the number of people working in the space industry, which will result in more innovations for everyone.

\subsection{Taxation Rate}

A recommended COST tax value would be slightly lower than the turnover rate [5]. For example, if a good changes ownership every 15 years or so, it has $6.67 \%$ chance to change owner every year, so a $5 \%$ annual tax rate is appropriate. Different types of assets (orbits, Moon areas, asteroids, Mars areas, ...) have different tax rates, and these rates can be adjusted whenever needed based on observed behaviours, by a vote from the OSA member states. In the first years, the tax rate could be kept very low so that COST values are declared high, and there are not many ownership changes, if any. This would encourage early investments and help cover the initially higher risks involved in financing such projects. In this case, the allocation should be overseen by a separate entity like the UNOOSA, to prevent resource locking and inappro- priate allocation. Property could for instance be granted after a given amount of exploration has been performed (imaging, sampling, ...).

At a tax rate of $5 \%$ for lands, an average Mars price of $1.4 \$$ ha would provide the OSA with $1 \mathrm{~B} \$$ yearly income. Around 30\$/ha, the OSA budget would match NASA's yearly budget. Farmland in France sells between $2 \mathrm{k}$ and $20 \mathrm{k} \$ / \mathrm{ha}$, but of course, these are open-air breathable areas. No other taxes are required to provide steady income to the OSA, considering the Moon is about the size of the African continent, and there are thousands of asteroids to exploit in the main belt.

\subsection{Exceptions}

Protected areas, like previous probes landing sites, rovers operating sites, north and south poles, and in general any area deemed protected for scientific, ethical, or any other reason, cannot be owned through the partial ownership system, and should require special requests to be issued before any interaction.

\subsection{Bootstrapping the Private Economy}

Private companies do not have to wait decades to join the game. With a Partial Ownership system in place, several business models could emerge today, leveraging the private sector funding capacities for a faster space infrastructure development effort and short/medium-term profit perspectives.

Space agencies will contract with major space industry companies to conduct their initial exploration activities, as is the case today. Including them in the process is crucial to prepare the transition to a privately-led economy, because the private sector can acquire knowledge and invest in facilities at a reduced risk. But with a resource utilization regulatory framework in place, start-up initiatives could emerge today, powered by the revolution in space launch costs and funded by audacious investors who see the unparalleled value of space exploitation and settlement. There is no doubt that if the American continent were discovered today, and a property and resource utilization framework could be enforced there, investments would be made to develop this new land of opportunities and support brave pioneers willing to dedicate their lives to the construction of a new world. Nations would have strategic interests in establishing facilities and a robust presence on this new continent and would do so. It is often said that the Moon is Earth's 8th continent, and with the ever-increasing reliability of space technologies and decreasing costs of making space hardware, it is becoming more and more evident that the last thing required for developing a sustainable human presence in space is a robust international legal framework. Mars is even easier to access than the Moon due to its atmosphere, and the resources available there 
arguably make it an even safer and more sustainable destination. After Mars has been tamed, supporting operations to the Asteroid belt will be more convenient and economic.

When a private company conducts geological surveys on the Moon, Mars, or Asteroids, they become aware of valuable locations holding useful materials. This information can be sold to the scientific community or stimulated a through bounty-based system. With the partial ownership system in place, the company can acquire the land, then increase the self-assessed value of these locations, in the prospect of future interested buyers. A business model for exploration companies can be supported. Similarly, other companies will wait for valuable locations to be discovered and buy these locations to send mining equipment that will perform resources extraction. Transport companies will be established to move all these extracted resources back to Earth orbit, the Moon, or to future Mars settlement areas, where other companies will be preparing the terrain, and building power distribution and piping networks. A whole private economy can be bootstrapped, the only missing element is a resource allocation framework.

\subsection{Social Dividend}

Some profits collected through the COST tax system could be redistributed as a universal basic income to space workers and settlers, providing them with a substantial amount of money. This would ensure that the expensive daily goods in space can be afforded by people living there. This is a very important point because life in space will be expensive and high-paying jobs or other sources of income are needed to make the trip appealing to the middle-class. Without high incomes in space, only tourists and individuals mandated by their employers (or military) will be able to make the trip. Providing space workers and settlers with a social dividend is a way for space capital holders to commonly incentivize migration to their land, and finance economic growth, because in the labour-short space economy, the limiting factor for expansion will be the number of people able to travel and live there.

The taxes collected through the COST system could also serve to build investment funds for supporting the new space start-up ecosystem and redistribute wealth so that over a very long period, the inequalities of starting capital will be evened out, and truly everyone can acquire the capacity to dispute the use of space resources, guaranteeing an effective resource allocation and an efficient space economy.

\section{Conclusions}

A brief overview of space law has been made, both through international treaties and national laws. It has been discussed how existing analogous situations to space, like the isolated, scientifically interesting, and resources-rich Antarctica, can be used as inspiration to establish an international legal framework to govern the use of outer space resources. A governance system based on the foundation of a new intergovernmental entity has been proposed, and its internal decision process based on radical democracy is depicted as a powerful tool to establish an international legal framework and regulate the use of common resources. The protection of our common lunar heritage is discussed, and a system based on protected areas like on Earth is proposed. A program of space citizenship is proposed to gradually transfer the governance power of space settlements from Earth-bound nations to new space-faring branches of human civilization gradually earning its independence. An economic structure based on partial ownership and the establishment of a Harberger tax is described, and it is shown that such mechanism would allow to benefit from the efficient allocation of market dynamics, while respecting the international agreements that prevent private property and claims of sovereignty, keeping the ownership of space resources shared between all spacefaring nations.

Open Access This article is licensed under a Creative Commons Attribution 4.0 International License, which permits use, sharing, adaptation, distribution and reproduction in any medium or format, as long as you give appropriate credit to the original author(s) and the source, provide a link to the Creative Commons licence, and indicate if changes were made. The images or other third party material in this article are included in the article's Creative Commons licence, unless indicated otherwise in a credit line to the material. If material is not included in the article's Creative Commons licence and your intended use is not permitted by statutory regulation or exceeds the permitted use, you will need to obtain permission directly from the copyright holder. To view a copy of this licence, visit http://creativecomm ons.org/licenses/by/4.0/.

\section{References}

1. The International Space Exploration Coordination Group (ISECG): Global Exploration Roadmap (GER), 3rd edition, 2018. https:// www.globalspaceexploration.org/wordpress/wp-content/isecg/ GER_2018_small_mobile.pdf. Accessed 21 Jun 2019.

2. United Nations Office for Outer Space Affairs (UNOOSA): Treaty on principles governing the activities of states in the exploration and use of outer space, including the moon and other celestial bodies ("Outer Space Treaty"), 1966. https://www.unoosa.org/oosa/en/ ourwork/spacelaw/treaties/outerspacetreaty.html. Accessed 21 Jun 2019.

3. About UN Membership, on the United Nations website, https:// www.un.org/en/sections/member-states/about-un-membership/ index.html. Accessed 21 June 19.

4. Lalley SP, Glen Weyl E (2018) Quadratic voting: How mechanism design can radicalize democracy. AEA Papers Proc 108:33-37

5. Radical Markets: Uprooting Capitalism and Democracy for a Just Society" by Eric A. Posner, E. Glen Weyl. Published May 15th, 2018 by Princeton University Press. ISBN 0691177503 (ISBN13: 9780691177502). 
6. Centre for a Spacefaring Civilization: Space Settlement Governance: An Analysis of Legal and Policy Issues, by Thomas Cheney, 2019. https://www.spacefaringcivilization.space/. Accessed 21 Jun 2019.

7. Zubrin R (2018) The economic viability of mars colonization. In: James T (ed) Deep space commodities. Palgrave Macmillan, Cham, pp $159-180$
8. United Nations Office for Outer Space Affairs (UNOOSA): Agreement Governing the Activities of States on the Moon and Other Celestial Bodies ("Moon Agreement"), 1979. https://www.unoosa. org/oosa/en/ourwork/spacelaw/treaties/intromoon-agreement.html. Accessed 21 Jun 2019. 